\title{
A ATUAÇÃO DO NEUPSICOPEDAGOGO NO EMPODERAMENTO DA APRENDIZAGEM
}

Fernanda da Silva Lage de Castro

Sidney Vergilio da Silva

\begin{abstract}
RESUMO
O neuropsicopedagogo é o profissional qualificado para reabilitar as funções neurofuncionais modificadas pelas dificuldades de aprendizagem. Entretanto, ainda são raras as escolas do país, públicas ou privadas, que têm esse profissional no seu quadro de especialistas para orientar pais, professores e alunos e explicar clinicamente o distúrbio e as condutas a serem executadas, além do tratamento e da intervenção. Este estudo tem como objetivos entender as dimensões do conceito empoderamento e de Neuropsicopedagogia; conhecer o processo de formação do neuropsicopedagogo; investigar como a atuação desse profissional pode contribuir para o empoderamento da aprendizagem. O neuropsicopedagogo pode ser a possibilidade mais apropriada, já que possui conhecimentos em Neurociência para compreender o cérebro e seu funcionamento. A aquisição de conhecimento, segundo Paulo Freire e outros autores, fortalece os sentimentos de autorrealização, identidade e pertencimento do indivíduo. A metodologia utilizada para realizar este estudo foi a pesquisa da literatura em artigos publicados, em livros e nas bases de dados e sites Scielo, Portal Educação, Psicologado, SBNPp e Nova Escola. Os resultados mostram que a Neuropsicopedagogia possibilita novos métodos de ensino e aprendizagem, embora as pesquisas e a literatura científica sobre o tema ainda sejam escassas. Ainda assim, acredita- se que a atuação do neuropsicopedagogo pode contribuir com a Educação, promovendo o empoderamento do aluno através do conhecimento e da educação.
\end{abstract}

\section{INTRODUÇÃO}

Este século de mudanças e desafios sobre educação, leva as instituições educacionais a olharem para o indivíduo de uma nova maneira, considerando o ambiente em que vive, as suas habilidades e dificuldades e o seu conhecimento prévio. Cabe ao educador adotar um trabalho no qual o estudante desenvolva a inteligência e as potencialidades.

Nesse cenário, a Neurociência dispõe de conhecimentos que podem inovar a forma de aprendizagem. A Neuropsicopedagogia, ciência que tem caráter transdisciplinar, baseia-se nos conhecimentos da Neurociência direcionados à Educação, juntamente com a Pedagogia e a Psicologia Cognitiva. É a ciência que tem por objetivo compreender os processos cerebrais pelos quais o homem percebe, aprende, age e lembra-se. Outro aspecto relevante é enfatizado por Relvas (2016) é que esta nova possibilidade de educar favorece a melhora da qualidade de vida e as condições de aprendizagem do aluno.

Em seu processo de formação, o neuropsicopedagogo recebe informações sobre o funcionamento do cérebro e das relações dos neurocognitivos para, então, atuar nas intervenções sociais e no crescimento humano do aluno. Tem domínio dos fundamentos neuropsicopedagógicos aplicados à aprendizagem, podendo, assim, aprimorar o ensino. 
Conforme entendem Domiciano e Rosa (2017), esse especialista está capacitado para implementar as intervenções para o crescimento humano do aluno, com o objetivo de aperfeiçoar a sua formação.

Quanto à sua atuação no empoderamento da aprendizagem, pode-se observar que a literatura ainda é escassa, mas há uma tendência de investimento na valorização e legitimação deste profissional no campo da Educação. Sua intervenção é fundamental nos processos que envolvem a integração de vários conhecimentos e na construção de conhecimento do aluno. Dar poder ao indivíduo, ou seja, empoderar, fortalece os sentimentos de realização, identidade e pertencimento à sociedade. Paulo Freire acreditava no professor capaz de coordenar a ação educativa, mas também no aluno como cidadão participante na sala de aula.

A pesquisa será realizada utilizando a leitura aprofundada de livros, artigos científicos e periódicos publicados no Scielo, Portal Educação, Psicologado, SBNPp e Nova Escola, utilizando-se os descritores "neurociências", "atuação do neuropsicopedagogo", e "empoderamento". Através da análise desta literatura, será possível organizar e obter maior esclarecimento sobre a temática, de forma a compreender a atuação do profissional que tem como ferramenta o conhecimento sobre o cérebro e seu funcionamento, fundamental para potencializar o processo de aprendizagem.

Usar a inteligência processando as informações é um princípio neurocientífico e o indivíduo é capaz de aprender e ressignificar novas aprendizagens com base nas experiências vividas na escola e na vida social. Este estudo justifica-se pela sua relevância no processo de construção de conhecimento do aluno. A função do neuropsicopedagogo consiste em mediar situações intencionais, analisando quais metodologias necessitam ser adotadas para ultrapassar as dificuldades de aprendizagem. Este profissional está habilitado a orientar no sentido de estimular novas sinapses, enquanto o aluno forma redes neuronais interligadas e consistentes, potencializando o processamento de informações, sentimentos, de emoções e de aprendizado.

Foi considerado como objetivo principal deste estudo analisar a atuação profissional do neuropsicopedagogo na educação, ressaltando a sua importância ao lidar com o processo de aprendizagem e promover o empoderamento dos alunos através da conquista de conhecimento. Como objetivos específicos este trabalho propõe-se a entender as dimensões do conceito empoderamento e de Neuropsicopedagogia; conhecer o processo de formação do neuropsicopedagogo; investigar como a atuação desse profissional pode contribuir para o empoderamento da aprendizagem.

\section{EMPODERAMENTO: DIMENSÕES HISTÓRICAS E CONCEITUAIS}

Os apontamentos reunidos por Baquero (2012) mostram que o verbo intransitivo empoderar constitui o processo no qual sujeito, organizações e comunidades garantem voz, influência, força de ação e decisão. Tem sido utilizado em áreas de conhecimento como educação, sociologia, ciência política, saúde pública, psicologia comunitária, serviço social e administração, com diversos sentidos. Empowerment, ou empoderamento, segundo informa Narayan (2002), tornou-se uma ferramenta útil para governos, organizações da sociedade civil e agências de desenvolvimento, significando a melhoria da qualidade de vida e dignidade humana de setores pobres, bem como boa governança, efetividade na prestação de serviços e responsabilização social. 
Segundo Baquero (2012), a Tradição do Empowerment (Empowerment Tradition) nasceu na Reforma Protestante, movida por Lutero, no século XVI, na Europa, lutando por justiça social. Nos Estados Unidos, o termo está presente nas lutas pelos direitos civis, no movimento feminista, na ideologia da "ação social", movimento dos homossexuais, dos negros e pelos direitos da pessoa deficiente. Na década de 1960, foi usado com sentido de emancipação social nos movimentos contra o sistema opressivo, nos movimentos de libertação e contracultura. Nos anos 1990, abraçou os movimentos que defendem o direito à cidadania sobre a prática médica, educação em saúde, a política, justiça e a ação comunitária.

Ainda citando o estudo de Barquero (2012), quanto ao empoderamento em nível individual, este envolve o nível psicológico de análise, ou seja, a habilidade do indivíduo de ganhar conhecimento e controle sobre a sua força pessoal. Significa aumento da capacidade de o sujeito se sentir atuante nos processos que definem sua vida. Na literatura, as publicações circulam em diversas disciplinas e práticas profissionais, sendo que, a maioria localiza-se nas

áreas de Saúde Pública, Psicologia Comunitária e Administração e, menos nas áreas da Sociologia e da Política.

Pode-se afirmar, segundo Vasconcelos (2003) apud Kleba e Wendausen (2009), que o empowerment recebeu influências teóricas europeia, anglo-saxônica e brasileira. As estratégias de empoderamento estão relacionadas ao processo de desenvolvimento econômico-social e à cultura democrática social. É a reapropriação de tradições e envolve lidar com o poder teórico, político, social e subjetivo e compreende aspectos cognitivos, afetivos e condutuais. É, também, aumento do poder, de autonomia pessoal e coletiva, nas relações interpessoais e institucionais, de grupos controlados pela opressão, discriminação e dominação social.

No Brasil, a palavra empoderamento possui dois sentidos mais utilizados. Segundo Kleba e Wendausen (2009), um deles é do processo de práticas destinadas a estimular grupos e comunidades para que melhorem suas condições de vida e sua autonomia. $\mathrm{O}$ outro sentido abrange as ações que integram excluídos carentes de bens indispensáveis à sobrevivência, serviços públicos e sistemas que os atendem através de ações assistenciais. Muitos autores optam por usar o termo na língua inglesa, empowerment, para conservar a autenticidade da tradução. $\mathrm{O}$ vocábulo tem sido associado à melhoria de posição de grupos vulneráveis e como ferramenta de controle por grupos que tentam dominar a distribuição de poder.

Sobre o empoderamento pessoal, as autoras citam que o mesmo sugere um processo de harmonia na comunidade, em que as várias maneiras de participação são espaços de aprendizagem e reconhecimento entre os elementos do grupo, fortalecendo os sentimentos de realização pessoal, identidade e pertencimento. Porém, o meio social deve impor limites sem sufocar a criatividade e a inovação. $\mathrm{O}$ empoderamento pessoal torna o indivíduo seguro de sua competência e capacidade, adquire compreensão crítica de seu lugar no mundo e nas relações sociopolíticas.

Entretanto, a obra de Paulo Freire (2006) apresenta outro conceito para empowerment. O autor cita o empoderamento de classe social, pois este não é um processo de caráter individual, e sim, uma ação social. O empoderamento individual baseia-se na crítica social e na transformação da sociedade. O sujeito detém o controle de sua vida por meio da interação com outros indivíduos, fortalecendo a sua capacidade pessoal junto a sua comunidade, modificando as relações de poder. Está relacionado à conscientização do indivíduo e esta conscientização acontece através do conhecimento e da prática, do diálogo homem-mundo e da ação-reflexão.

Na Educação, destaca-se a obra de Paulo Freire. A educação pode mudar o entendimento 
da realidade que, por sua vez, pode provocar a ação política na sociedade para realizar a transformação social. A educação é um ato político, um projeto social. Para Freire (1979, p. 34), "a educação, como prática de liberdade, é um ato de conhecimento, uma aproximação crítica da realidade".

Por não existir o vocábulo "empoderamento" na língua portuguesa, dos vários sentidos existentes que dificultam a tradução fiel do termo empowerment para o português, o presente estudo utilizará o conceito elaborado por Paulo Freire.

\section{NEUROPSICOPEDAGOGIA}

Nas expressões de Cosenza e Guerra (2011), a profissão docente pode ser mais producente quando o educador possui conhecimento sobre o funcionamento do cérebro. Quando o educador conhece a organização e as funções cerebrais, a estrutura da linguagem, atenção e da memória, as ligações entre cognição, emoção, motivação e desempenho, as dificuldades de aprendizagem e as intervenções a elas relacionadas contribui para o cotidiano do educador na escola, junto com o aluno e a família. Entretanto, somente saber como o cérebro aprende não basta para que ocorra o fenômeno do ensinar e aprender.

Como aponta de modo recorrente a literatura e é lembrada por Sousa (2018), a Educação ganhou o auxílio de uma ciência que se dedica a assessorar o profissional clínico e institucional com o fim de aprimorar a aprendizagem. Conhecida como Neuropsicopedagogia, esta ciência tem caráter transdisciplinar e se apoia nos conhecimentos da Neurociência voltados à Educação, em conexão com a Pedagogia e a Psicologia Cognitiva. É a parte da ciência que visa compreender os processos mentais pelos quais o homem percebe, aprende, age e se lembra.

Acrescente-se que Relvas (2016) afirma que a Neurociência da Educação pode ser definida como a investigação da estrutura, do desenvolvimento, do amadurecimento e do funcionamento do sistema nervoso, observando-se os aspectos biológico, neurobiológico, psicológico, matemático, físico, filosófico e computacional, direcionado para a aquisição de informações, solução de problemas e modificações comportamentais. Isto possibilita práticas educativas que beneficiam a qualidade de vida e melhores condições de aprendizagem.

O estudo de Borges (2016) aponta que a ciência que se dedica ao estudo do cérebro e seu funcionamento, à medida que progride acrescenta informações para a melhor compreensão do aprendizado como fenômeno da ação educacional. $\mathrm{O}$ homem percebe o mundo por meio dos sentidos e da memória. Izquierdo (2002) apud Borges (2016) relata que esta aquisição é denominada aprendizagem e, somente se "grava" o que foi aprendido; a evocação é chamada de lembranças. Lembramos aquilo que gravamos, isto é, aquilo que foi aprendido.

Conforme cita Borges (2016), a criança desenvolve seus conhecimentos sobre a leitura e a escrita passando por hipóteses, apoiada em conhecimentos prévios e assimilações que dependem do intercâmbio dela com os sujeitos de seu meio. O processo ensino-aprendizagem permite o entendimento do aprender, além do ensinar, podendo ultrapassar as dificuldades do aprendiz e daquele que ensina, para, assim, encontrar condutas que melhorem o ensino e a aprendizagem. $\mathrm{O}$ ato de aprender não é apenas uma questão de memorizar os conteúdos, mas compreende as emoções, a interação, a alimentação, o descanso e a motivação.

Segundo destaca Oliveira $(2018$, p. 4), a Neuropsicopedagogia estuda a relação entre "o funcionamento do sistema nervoso e a aprendizagem humana numa perspectiva de reintegração 
pessoal, social e educacional”. Para a SBNPp, ainda que a Neuropsicopedagogia clínica pesquise o funcionamento do cérebro e o comportamento humano, tem a base de sua práxis nas teorias para o ensino-aprendizagem. A estrutura teórica da formação do neuropsicopedagogo institucional e clínico está associada à Neurociência e à Educação.

\subsection{Neuropsicopedagogo: formação e capacidades}

Vários autores serviram de baliza para entender o processo de formação de educadores, sobretudo do neuropsicopedagogo. Segundo escreveram Domiciano e Rosa (2017), desse profissional é exigida a compreensão das questões ligadas ao funcionamento cerebral e das relações complexas dos neurocognitivos e a sua participação nas intervenções estratégicas na esfera social e no crescimento humano. Este especialista é instruído para apreender quais são os fundamentos neuropsicopedagógicos aplicados à aprendizagem para aprimorar o ensino.

De acordo com Socoz (2016), é possível observar que, ainda que a Neurociência possa oferecer contribuições para a descrição científica das funções e atividades do cérebro, é preciso ser prudente, pois somente este conhecimento não é o bastante para mudar a experiência do sujeito. Mas, é inegável que a Educação, ao tomar de empréstimo os conhecimentos à Neurociência, pode aperfeiçoar o processo de aquisição de conhecimento no sentido de entender os transtornos e as dificuldades de aprendizagem.

Para a autora, é comum encontrar-se nos cursos de formação de educadores conteúdos e trabalhos técnicos, incutindo no profissional a ideia de que adquirindo novos saberes ocorrerão as sonhadas alterações no processo de ensino e aprendizagem. Mas, ressalta que a observação da forma como o professor aprende, a sua trajetória nos cursos formativos e a sua experiência na vida escolar é que vão determinar a sua atuação como educador.

Com base nesses argumentos, Socoz (2016), afirma que as emoções produzidas no contexto de ensino-aprendizagem podem causar insegurança e interesse, bem como entusiasmo ou desilusão. Então, o aspecto afetivo não pode deixar de ser considerado, pois interfere no trabalho do educador. Durante o ensino e a aprendizagem o docente se envolve com o estudante e suas dificuldades, mas também com as suas próprias dificuldades pessoais e profissionais. Nota-se que a perspectiva de mudança não se limita ao aluno, mas também o profissional aprende e pode passar por mudanças de comportamento.

A Neurociência pode colaborar para a inovação das teorias educacionais na formação docente. Conforme declara Cunha (2015), estas inovações acontecem por meio das informações científicas para a compreensão da aprendizagem. Este é o olhar atual sobre as mudanças desejadas e necessárias à Educação. Segundo o destaque feito por Carvalho (2010), a Organização de Cooperação e Desenvolvimento Econômicos (OCDE) voltou sua atenção para este aspecto, ao observar a força das ações educativas no crescimento de um país e criou o Centro de Pesquisa Educacional e Inovação (CEDI) que tem financiado estudos fundados no intercâmbio entre educação e Neurociência.

Ainda nesta linha de pensamento, Santos (2015) afirma que a Neuropsicopedagogia tem a avaliação, o diagnóstico e a intervenção como bússola da investigação do sujeito, da família, da escola e da sociedade nas quais o aluno vive. É, pois, uma práxis apoiada nas teorias e é uma área que possibilita intervenção e especialização e institui novas possibilidades de aprender sobre o aprender e outras interações entre conhecimentos.

O estudo de Rosário et al (2018) mostra que o neuropsicopedagogo, em uma escola, está 
capacitado para realizar avaliação e intervenção associadas aos transtornos de aprendizagem. É o profissional capaz de provocar novas sinapses, para o processo ensino- aprendizagem, já que conhece o sistema nervoso, o cérebro e a trajetória que determinados estímulos percorrem no corpo humano para produzir conhecimento. Da sua formação fazem parte orientações sobre o funcionamento e falhas do sistema nervoso que interferem na aprendizagem. Pode conduzir e monitorar o aluno no processo de construção de conhecimento, aplicando os conhecimentos da Neurociência, Psicologia e Pedagogia.

Na formação pedagógica do neuropsicopedagogo, conforme revelam Rosário et al (2018, p. 9), o conhecimento o capacita a apreender o modo como o "cérebro recebe, seleciona, transforma, memoriza, arquiva, processa e elabora as sensações assimiladas pelos diversos elementos sensoriais" e, a partir daí, adaptar métodos e técnicas educacionais àqueles com características cognitivas e emocionais diferenciadas. $\mathrm{O}$ profissional deve buscar os conhecimentos sobre as degenerações neurológicas, psiquiátricas e distúrbios e assim trabalhar no acompanhamento pedagógico, cognitivo e emocional do aluno que apresenta esses sintomas.

Em sua obra, Agra-Galvão (2017) informa que há um movimento de crescimento das pesquisas em Pedagogia que bebe da água da Neurociência Cognitiva, situação diferente de quando as investigações da Neurociência Cognitiva eram aplicadas à área da Saúde. Nota-se a introdução dos conteúdos importados da Neurociência à Educação, surgindo o "neuroeducador", isto é, o profissional que atuaria como uma ponte, para aplicar as descobertas da Neurociência na sala de aula. Uma parte de sua lida profissional seria remover as barreiras que impedem a junção do conhecimento científico ao saber educacional sobre o processo ensino-aprendizagem.

Sobre esses argumentos, Agra-Galvão (2017) acrescenta que este profissional poderia solucionar algumas dificuldades, pois as informações neurocientíficas seriam analisadas por aquele que também conhece a vida escolar, transpondo a linguagem científica da Neurobiologia para a área educacional e vice-versa. É fundamental que o professor possua conhecimentos que o capacite a ensinar, motivar e avaliar o aluno de maneira eficiente e ajustada com o funcionamento do seu cérebro. Portanto, inserir os conteúdos de Neurociência nos cursos de formação de professores deve ocorrer de modo organizado, visando à práxis, à apropriação e aplicação destes saberes e seus princípios na escola.

\subsection{O neuropsicopedagogo e sua atuação no empoderamento da aprendizagem}

Conforme orienta o artigo 29 da SBNPp (2016), a especialização lato sensu em Neuropsicopedagogia considera duas áreas de atuação, isto é, a Neuropsicopedagogia institucional e a clínica. Segundo o artigo, o neuropsicopedagogo, com formação na área Institucional, atua exclusivamente em ambientes escolares e instituições de atendimento coletivo. Trabalha em equipe multidisciplinar, realizando triagens para encaminhamentos aos profissionais da saúde, incluindo as crianças e adolescentes em oficinas pedagógicas e acompanhando o seu desempenho na escola.

No que se refere às atribuições do neuropsicopedagogo, a SBNp (2016) descreve que suas atividades abrangem diferentes instituições e possibilidades de intervenções. Nas instituições acadêmicas esse profissional pode realizar pesquisas, trabalhar na área de ensino e supervisão. Nas instituições hospitalares, forenses, clínicas, consultórios privados e atendimentos domiciliares pode efetuar diagnóstico, reabilitação, orientação à família, bem como trabalho em equipe multiprofissional. Faz parte de sua prática ressaltar que os exames neuropsicológico, 
neurológico e o exame geral são fundamentais e se complementam.

Na escola, o profissional de Neuropsicopedagogia, poderá atuar junto aos pais explicando clinicamente o distúrbio e as condutas a serem executadas, com o objetivo de colocar em prática um processo organizado de tratamento e intervenção, tornando a família como a autora do êxito da intervenção. Este atendimento interdisciplinar deverá ser efetivado com a participação do orientador educacional. Segundo o Código de Normas Técnicas 01/2016, da Sociedade Brasileira de Neuropsicopedagogia, SBNPp (2016), no Artigo 29, as funções do neuropsicopedagogo se resume em:

a) Observação, identificação e análise do ambiente escolar nas questões relacionadas ao desenvolvimento humano do aluno nas áreas motoras, cognitivas e comportamentais, considerando os preceitos da Neurociência aplicada à Educação, em interface com Pedagogia e Psicologia Cognitiva;

b) Criação de estratégias que viabilizem o desenvolvimento do processo ensino- aprendizagem dos que são atendidos nos espaços coletivos;

c) Encaminhamento de pessoas atendidas a outros profissionais quando o caso for de outra área de atuação / especialização contribuir com aspectos específicos que influenciam na aprendizagem e no desenvolvimento humano. (SBNp, 2016, p. 4).

O neuropsicopedagogo pode atuar também como clínico, porém o viés dessa pesquisa está voltado para as questões escolares e a atuação do profissional no empoderamento da aprendizagem. É importante lembrar que, atualmente, têm sido divulgadas as possibilidades de novas estratégias e metodologias da Neuropsicopedagogia na Educação a serem aplicadas no processo ensino-aprendizagem. Para Avelino (2019), estas possibilidades se alicerçam na integração de conhecimentos de áreas diversas, incluindo comportamentos, pensamentos, emoções, movimentos e efetividade. Assim, o motor neuropsicopedagógico é encontrar tratamentos para distúrbios, transtornos e dificuldades de aprendizagem que impedem ou dificultam o êxito na aquisição de conhecimento.

$\mathrm{O}$ autor reitera que, ao profissional compete examinar necessidades cognitivas do estudante, para que a intervenção seja instigante, com atividades que acompanhem o ritmo de seu crescimento. Na escola ou fora dela, o trabalho neuropsicopedagógico inclui a recomendação de exercícios de estímulos que auxilie as atividades cerebrais. Esse profissional

monitora os processos didático-metodológicos no cotidiano escolar, voltando a sua atenção para os alunos que apresentem transtornos diversos ou dificuldade de assimilar o processo ensinoaprendizagem e que, por isso, precisam de cuidados em seu tempo de aprendizagem.

Segundo Avelino (2019), considerando as atribuições do profissional, conhecendo as funções neurofuncionais de estudantes com limitações, sua atuação adquire importância para o processo educacional ao empregar soluções como entrevistas que avaliam a expressão e os comportamentos em busca do diagnóstico educacional. Seu conhecimento em distúrbios e processos de aprendizagens permite que diagnostique e encaminhe a outros especialistas utilizando pareceres e laudos. Entre os distúrbios destacam-se aqueles relacionados à leitura, a escrita, a matemática, a déficits visuais, motor, transtornos emocionais e desenvolvimento 
intelectual.

Ainda segundo o autor, depois de pronto o diagnóstico de outros especialistas, o neuropsicopedagogo trabalhará junto com a família, a fim de promover a intervenção pedagógica, visando ao progresso do aluno e respeitando as suas limitações. Para a escola inclusiva, a presença desse profissional especialista pode ser um apoio diário importante, tanto nos temas pedagógicos, quanto psicológicos para dar impulso à aprendizagem eficaz. Para Sousa (2018), o neuropsicopedagogo deve ser capaz de reabilitar as funções neurofuncionais modificadas pelas dificuldades de aprendizagem, atendendo alunos ou oferecendo ferramentas para que professores utilizem metodologias e estratégias educacionais adequadas.

De acordo com Avelino (2019), ainda são poucas as escolas do país que possuem esse profissional para orientar pais, professores e alunos. Nota-se, a escassez de investimentos e o reconhecimento da profissão, exceto algumas instituições escolares particulares e públicas da Educação Básica. Desse modo, a escola e o cérebro, cada um com suas funções específicas podem privilegiar o desenvolvimento cognitivo e o êxito do aluno.

Segundo Domiciano e Rosa (2017), a partir de sua formação, o profissional está qualificado para elaborar alternativas para o desenvolvimento do aluno e promover a aproximação entre professores, pais e escola a fim de dar prosseguimento ao processo ensinoaprendizagem. $\mathrm{O}$ neuropsicopedagogo sabe que quem ensina, ensina a alguém, então, o educador deve adequar a sua forma de ensinar à forma de como esse alguém aprende. A Neuropsicopedagogia traz o conhecimento para identificar as melhores práticas.

Afirmam as autoras que o neuropsicopedagogo tem responsabilidades: a) desmistificar o fracasso escolar, o que exige um combate sistêmico; b) ajudar a escola a assumir sua responsabilidade no fracasso educacional. Até hoje o sistema credita ao aluno este resultado, por considerá-lo malandro com relação aos estudos, alegando que o aluno tem transtornos de aprendizagem ou que falta a colaboração da família. c) compartilhar o conhecimento neurocientífico. Este profissional precisa auxiliar os professores a entenderem o funcionamento cerebral e a prepararem aulas que incentivem este funcionamento.

Como aponta Silva et al (2016), no processo de ensino-aprendizagem, o educador é educando e o educando é professor ao mesmo tempo, portanto, todos ensinam e aprendem juntos. Este é um método de trabalho que tem como pilar de sustentação o diálogo e a relação horizontalizada. O diálogo se dá de modo crítico e criativo, indicando que o conhecimento é construído nesta relação onde os temas devem ser pensados e percebidos por esses atores por meio da realidade.

Conforme relatam os autores, ao ter consciência de sua presença na comunidade e no mundo e na sua capacidade de modificar sua realidade, o indivíduo se sente capaz de descobrir caminhos para a sua emancipação social, política e cultural, pode ir mais longe. Se assim é, a educação tem um tipo de empoderamento que promove o processo de conscientização no aluno. Assim, escola, educadores e neuropsicopedagogos estarão construindo ambientes para empoderar alunos através do conhecimento e da educação.

Segundo comentam Kleba e Wendausen (2009), o empoderamento pessoal é um campo de aprendizagem e reconhecimento, no qual o indivíduo é aceito como membro de um grupo. Igualmente Cunha (2015) escreve que é fundamental a mediação intencional, sistematizada e pedagógica no processo de aquisição do conhecimento. O professor ou neuropsicopedagogo é o mediador na aprendizagem do aluno, é o facilitador nas estratégias de ensino que se propõe a desenvolver. É indispensável que a escola se torne espaço que acolhe a diversidade, conduzindo 
o aluno para vida, ensinando-o a ser cidadão.

Os estudos da Neurociência têm avançado e os resultados das pesquisas têm sido aplicados em diversas áreas. Nesse sentido, o trabalho do neuropsicopedagogo está sendo definido à medida que sua prática se estabelece nas instituições. Segundo Oliveira (2018), este se dedica a estudar a causa das dificuldades de aprendizagem, o diagnóstico, a reabilitação e a prevenção das dificuldades e distúrbios. Mas, o neuropsicopedagogo, que em sua formação adquire conhecimentos em Neurociência, observando a queixa principal e o quadro de sintomas, está habilitado a redigir pareceres de encaminhamento para neurologistas, pediatras e psiquiatras, auxiliando-os na identificação de possíveis patologias.

Para esta autora, na escola, o neuropsicopedagogo pode contribuir com o trabalho do professor, sobretudo quando o tema é fracasso escolar, repetência e evasão escolar. De posse dos conhecimentos da Neurociência é capaz de trabalhar com estes estudantes. Pode ser decisivo na abordagem e solução da dificuldade de aprendizagem na fase de alfabetização, contribuindo para a evolução de habilidades como ler e escrever, questões motoras, de raciocínio lógico, atenção, memória. Um dos seus objetivos é identificar as causas daquelas dificuldades, tendo como base a etiologia do problema fundamentado nos tipos de transtornos biopsico e sociofamiliar.

No entanto, segundo anota Carvalho e Villas Boas (2018), ainda que haja procura pelo saber em Neurociência, no que se refere à ação prática, esta é embrionária. Mesmo que exista a relação crescente entre Neurociência e Educação, não é comum um pesquisador em Neurociência examinar a literatura especializada em Educação para representar suas hipóteses. Mas também é incomum um pesquisador da Educação examinar a literatura neurocientífica. Essa falta de diálogo entre as áreas pode ser percebida pela falta de citações de trabalhos de pesquisadores nos dois sentidos.

Os autores acreditam que esta falta de integração deve-se aos neurocientistas que, ao redigirem sobre educação, se dirigem aos seus pares neurocientistas. Isso dificulta o entendimento para pessoas que não dominam o conhecimento de conceitos biológicos. Citam como exemplo a revista Mind, Brain and Education que investiga sobre como o sistema nervoso funciona durante o processo educacional e apresenta sua escrita em linguagem científica de difícil compreensão para o professor ou educador que não são daquela área. Isto compromete a forma como o ensino é orientado na sala de aula.

Conforme relata Santos (2015), o profissional de Neuropsicopedagogia terá uma base teórico-prática consolidada para entender funções cognitivas como atenção, memória, tátilcinestésica, funções motoras, linguagem, planejamento, julgamento e orientação. A meta de estudo depende da aquisição e do aperfeiçoamento do conhecimento técnico-científico das pesquisas sobre as anomalias neurológicas, psiquiátricas e distúrbios psicológicos do aluno. Tendo como alicerce a Neurociência, o neuropsicopedagogo deve ser aprendiz e pesquisador de sua práxis, aquele que expande a sua percepção do ser humano e responde a questões sobre o funcionamento do cérebro, de como somos, como nos desenvolvemos e aprendemos.

De acordo com o estudo realizado por Reimers (2012), educação significa empoderar indivíduos para que tenham condições de ampliar suas liberdades e se tornar elementos efetivos nas comunidades nas quais se inserem. Esse é o papel da educação. E, quando se fala em inovar na Educação significa encontrar maneiras efetivas de empoderar esses sujeitos.

$\mathrm{O}$ autor comenta que, normalmente, as escolas se dedicam somente às competências acadêmicas. Não há um plano de trabalho direcionado a outras habilidades para que o aluno se 
torne um sujeito independente e participe em sua comunidade. Portanto, são escassas as propostas para cultivar as capacidades sociopsicológicas, como a resiliência, a perseverança, a empatia e a habilidade para trabalhar em grupo e aprender com o erro. Uma possibilidade de inovação é a educação on-line, por meio de esportes, modificando a estrutura física da escola e no modo como é financiado um projeto.

Embora não tenha sido citado o vocábulo empoderamento, é coerente supor que, no estudo de Santos (2015), ao estimular o aluno a utilizar a inteligência, a memorizar, a armazenar e trazer as informações e convertê-las em conhecimento é a constatação de que este produziu aprendizagem, partindo das próprias experiências. $\mathrm{O}$ ato de usar a inteligência e processar as informações é um princípio da Neurociência, que considera o sujeito possuidor de possibilidades de aprender e ressignificar novas aprendizagens com base nas experiências vividas na escola e na vida social.

A autora explica que, desse modo, o indivíduo realiza novas sinapses e forma redes neuronais interligadas e consistentes, gerando maior velocidade das redes de interligações das sinapses maximizando o processamento de informações, sentimentos, de emoções, de aprendizado capaz de reorganizar a funcionalidade das conexões e a estrutura do cérebro. Por isso, Lima (2017) entende que o olhar do neuropsicopedagogo precisa ser criterioso e sistêmico, pois tem responsabilidade na mediação das situações intencionais, analisando quais metodologias necessitam ser adotadas para ultrapassar as dificuldades de aprendizagem.

Sobre a atuação do neuropsicopedagogo no empoderamento da aprendizagem, durante a realização deste trabalho pode-se observar que a literatura é escassa. Neste sentido, Lima (2017) relata que, sobre a sua atuação, as "breves e tímidas referências" indicam que sua presença é importante no processo de ensino-aprendizagem para a compreensão dos problemas e dificuldades da aprendizagem escolar. Entretanto, há uma tendência de investimento na valorização e legitimação deste profissional na Educação, pois esta é feita de processos que envolvem a integração de vários conhecimentos e a construção ou desconstrução de modelos já conhecidos e experimentados.

\section{CONCLUSÃO}

O objetivo principal deste estudo foi analisar a importância do neuropsicopedagogo ao promover o empoderamento dos alunos através da conquista de conhecimento. Como objetivos específicos este trabalho se propõe a entender as dimensões do conceito empoderamento e de Neuropsicopedagogia; conhecer o processo de formação doneuropsicopedagogo; investigar como a atuação desse profissional pode contribuir para o empoderamento da aprendizagem.

A Neuropsicopedagogia começa a ganhar corpo, se caracterizando como um campo multi e interdisciplinar, que oferece possibilidades na pesquisa educacional com a finalidade de tratar o conhecimento e a inteligência, integrando a Psicologia, a Educação e a Neurociência. O neuropsicopedagogo precisa conhecer as teorias que descrevem os processos neuropsicológicos envolvidos na aprendizagem para, então, desenvolver metodologias de ensino com qualidade.

O neuropsicopedagogo deve identificar as dificuldades do aluno e incentivá-lo, demonstrando que acredita em seu potencial e procurar minimizar as barreiras, a fim de facilitar a aprendizagem. É a partir desta intervenção que o profissional pode estimular o empoderamento educacional do aluno.

Notou-se que existe procura pela Neuropsicopedagogia, mas tanto nas pesquisas, quanto 
a presença do neuropsicopedagogo em escolas públicas e privadas ainda são tímidas. A Neuropsicopedagogia vem trazendo contribuições para educação como, por exemplo, ao incentivar o aluno a utilizar a memorizar, a armazenar e trazer as informações é a confirmação de que este produziu conhecimento. $\mathrm{O}$ neuropsicopedagogo pode contribuir a dificuldade de aprendizagem na alfabetização, promovendo o avanço das habilidades ler e escrever, questões motoras, de raciocínio lógico, atenção, memória.

Percebeu-se que há uma tendência de investimento na legitimação deste profissional da Educação, pois sua formação envolve a integração de vários conhecimentos. Por saber qual a melhor abordagem para sanar as dificuldades, o neuropsicopedagogo pode auxiliar os docentes a reorganizarem suas aulas e a maneira de ensinar. Pode atuar junto ao aluno e auxiliá-lo em suas dificuldades, promovendo o seu empoderamento através de estratégias e técnicas aprendidas em sua formação.

Apesar das observações obtidas na investigação, este estudo indica que há necessidade de mais pesquisas sobre o tema, considerando outros materiais, estudos que avaliem os resultados do trabalho realizado por neuropsicopedagogo voltado para o empoderamento educacional do aluno.

\section{REFERÊNCIAS}

ARTIGO COMENTADO do Código de Ética Técnico Profissional. Definições e proposições de diferenças na atuação Neuropsicopedagógica, 2016. Disponível em: <https://jupinheiro.com.br/artigos/pdf/NEUROPSICOPEDAGOGO-INSTITUCIONAL-E- CL\%C3\%8DNICOArtigo-Comentado>. Acesso em 17 Ago. 2019.

AGRA-GALVÃO, Sirlândia Kelis Pereira. Implicações da neurociência cognitiva na prática pedagógica de professores de biologia. Universidade Federal de Ouro Preto. Instituto de Ciências Exatas e Biológicas - ICEB. Mestrado profissional em ensino de Ciências - MPEC, 2017. Disponível em:<https://www.repositorio.ufop.br/bitstream/123456789/7623/1/DISSERTA\%C3\%87\%C3\%8 3O_Implica\%C3\%A7\%C3\%B5esNeuroci\%C3\%AAnciaCognitiva.pdf> Acesso em 21 Ago. 2019. AVELINO, Wagner Feitosa. A Neuropsicopedagogia no cotidiano escolar da Educação Básica. Revista Educação em Foco, n. 11, a. 2019. Disponível em:<http://portal.unisepe.com.br/unifia/wpcontent/uploads/sites/10001/2019/06/003_A- NEUROPSICOPEDAGOGIA-NO-COTIDIANOESCOLAR-DA- EDUCA\%C3\%87\%C3\%83O-B\%C3\%81SICA.pdf>. Aceesso 02 Set. 2019.

BAQUERO, Rute Vivian Ângelo. A situação das Américas: democracia, capital social e empoderamento. Empoderamento: instrumento de emancipação social? - uma discussão conceitual. Revista Debates, Porto Alegre, v. 6, n. 1, p.173-187, jan.-abr. 2012. Disponível em: https://seer.ufrgs.br/debates/article/viewFile/26722/17099>. Acesso em 02 Set. 2019. BORGES, Ângela Maria Rodrigues. Como a neuropsicopedagogia aperfeiçoa a aprendizagem na educação especial em Marabá, 2016. NAIA-UNIFESSPA. III CONGRESSO PARAENSE DE EDUCAÇAO ESPECIAL. Marabá-PA. Disponível em:

<https://cpee.unifesspa.edu.br/images/Anais_2016/Relatos_de_experiencia/Angela_Maria_Ro drigues.pdf >. Acesso em 14 Set. 2019.

CARVALHO, Fernanda Antoniolo Hammes de. Neurociências e educação: uma articulação necessária na formação docente. Trabalho, Educação, Saúde. Rio de Janeiro, v. 8, n. 3, p. 537-550, Nov. 2010. Disponível em: <http://www.scielo.br/scielo.php?script=sci arttext\&pid=S1981-77462010000300012\&lng=en\&nrm=iso>. Acesso em 8 Ago. 2019. CARVALHO, Diego de; Cyrus Antônio VILLAS BOAS. Página Aberta. Neurociências e formação de professores: reflexos na Educação e Economia. Ensaio: Aval. Pol. Públ. Educ., Rio de Janeiro, v. 26, n. 98, p. 231-247, Jan./Mar., 2018. Disponível em: 
<http://www.scielo.br/pdf/ensaio/v26n98/1809-4465-ensaio-26-98-0231.pdf>. Acesso em 15 Ago. 2019. COSENZA, Ramon M.; GUERRA, Leonor B. Neurociência e Educação, como o cérebro aprende. Porto Alegre: Artmed, 2011.

CUNHA, Polyana A. F. Neurociência e educação: a estimulação cognitiva como possibilidade de intervenção na educação inclusiva. Monografia. Especialização em Desenvolvimento Humano e Inclusão Escolar.

Departamento de Psicologia Escolar e Desenvolvimento Humano. Brasília: Universidade de Brasília - UnB, 2015. Disponível em:

<http://bdm.unb.br/bitstream/10483/15833/1/2015_PollyanaAparecidaFCunha_tcc.pdf >. Acesso em 21 Jul. 2019.

DOMICIANO, Giselli Cristini. ROSA, Bárbara Madalena Heck da. Como o neuropsicopedagogo pode auxiliar famílias de crianças com transtorno do espectro autista. Revista Científica Multidisciplinar Núcleo do Conhecimento. Ed. 07, a. 2, v. 1. p. 117-127, 2017.Disponível

<https://www.nucleodoconhecimento.com.br/educacao/neuropsicopedagogo>. Acesso em 27 Out. 2019.

FREIRE, Paulo. Conscientização. São Paulo: Cortez e Moraes, 1979.

FREIRE, P. \& SHOR, Ira. Medo e ousadia: o cotidiano do professor. 11 ${ }^{\text {a }}$ ed. Rio de Janeiro: Paz e Terra, 2006.

KLEBA, Maria Elisabeth; WENDAUSSEN, Agueda. Empoderamento: processo de fortalecimento dos sujeitos nos espaços de participação social e democratização política. Revista Saúde Soc. São Paulo, v.18, n. 4, p. 733-743, 2009. Disponível em:

<http://www.scielo.br/scielo.php?script=sci_arttext\&pid=S0104-12902009000400016>. Acesso em 30 Ago. 2019.

LIMA, Francisco Renato. Sentidos da intervenção neuropsicopedagógica nas dificuldades de aprendizagem na pré-escola. EDUCA-Revista Multidisciplinar em Educação, v.4, n.7, p. 78-95, Jan./Abr., 2017. Disponível em:

<http://www.periodicos.unir.br/index.php/EDUCA/article/view/2012>. Acesso em 12 Set. 2019.

NARAYAN, Deepa. Empoderamiento y redución de la pobreza: libro de consulta. Coimbra: World Bank, Alfa Ômega, 2002.

OLIVEIRA, Daliane. A neuropsicopedagogia pode transformar a atuação do educador. 2018. Disponível em: <https://blog.psiqueasy.com.br/2018/04/23/a-neuropsicopedagogia- pode-transformar-a-atuacao-doeducador/>. Acesso em 13 Out. 2019.

REIMERS, Fernando. Educar é empoderar pessoas para expandir suas liberdades. 2012. Disponível em: <http://porvir.org/fernando-reimers/>. Acesso em 12 Ago. 2019.

RELVAS, Marta Pires. Neurociência do aprendizado e a sala de aula. In: METRING, Roberte;

SAMPAIO, Simaia. (orgs.). Neuropsicopedagogia e aprendizagem. Rio de Janeiro: Wak Editora, 2016, p. 199-205.

ROSÁRIO, Samuel Antônio Silva do; ROSÁRIO, Jocenilda Pires de Sousa do; SANTOS, Valéria de Cássia Sales dos. A importância da atuação do neuropsicopedagogo para minimizar o baixo rendimento escolar a partir dos casos de bullying. Revista Atlante: Cuadernos de Educación y Desarrollo, Set. 2018. Disponível em:

<https://www.eumed.net/rev/atlante/2018/09/atuacao-neuropsicopedagogo-bullyng.html

//hdl.handle.net/20.500.11763/atlante1809atuacao-neuropsicopedagogo-bullyng.html>. Acesso em 21

Ago. 2019.

SANTOS, Lucília Silva. A atuação do neuropsicopedagogo frente ao combate do insucesso

$$
\text { escolar. } 2015 . \quad \text { Portal da Educação. Disponível }
$$

<https://www.portaleducacao.com.br/conteudo/artigos/psicologia/a-atuacao-do-

neuropsicopedagogo-frente-ao-combate-do-insucesso-escolar/67602>. Acesso em 17 Set. 2019.

SBNPp. Código de Ética Técnico Profissional da Neuropsicopedagogia, 2016. Disponível online em: <www.sbnpp.com.br>. Acesso em 15 Ago. 2019.

SILVA, Lucas Vieira de Lima; PINHEIRO, Maria Rosângela Dias; CHAGAS, Nilmara Serafim. O empoderamento como processo de conscientização e os sujeitos da educação. III CONEDU, Congresso Nacional de Educação. 2016. Disponível em: <http://www.editorarealize.com.br/revistas/conedu/trabalhos/TRABALHO_EV056_MD1_SA 6_ID566_18082016135045.pdf>. Acesso em 19 Out. 2019.

SOCOZ, Beatriz Judith Lima. A Psicopedagogia diante dos desafios dos problemas de aprendizagem. In: METRING, Roberte; SAMPAIO, Simaia. (orgs.). Neuropsicopedagogia e aprendizagem. Rio de Janeiro: Wak 
Editora, 2016, p. 207-215.

SOUSA, Linete Oliveira de. A contribuição da educação emocional positiva para a neuropsicopedagogia: (re) construindo o processo de ensino e aprendizagem. 2018. Disponível em: <https://sbnpp.org.br/acontribuicao-da-educacao-emocional-positiva-para-a- neuropsicopedagogia-re-construindo-o-processo-deensino-e-aprendizagem/>. Acesso em 19 Set. 2019. 